\title{
¿Es realmente cívico el nacionalismo catalán y étnico el vasco?
}

\author{
Julen Zabalo \\ Universidad del País Vasco. Escuela Universitaria de Trabajo Social \\ Los Apraiz, 2. 01006 Vitoria-Gasteiz \\ cipzabij@vc.ehu.es
}

\section{Resumen}

Una forma de tipificar los nacionalismos, referente al tipo de nación que se propone, diferencia entre nacionalismo político, territorial o cívico y nacionalismo étnico o cultural. Por otra parte, el nacionalismo, y menos en las naciones sin estado, no puede entenderse sin su vertiente política, lo que no significa interpretarlo de manera politizada. Eso sucede, a mi entender, en los casos catalán y vasco, los cuales son presentados como modelos opuestos: cívico e inclusivo el primero; y étnico y exclusivo el segundo. Sin embargo, su concepción de la nación resulta bastante similar, y lo que sí los separa es la práctica política. La caracterización de incluyente o excluyente del nacionalismo está, así, unida a su radicalidad política y no, al carácter de la nación. Considero que la nación y el tema nacional tienen unas características propias, y no podermos trasladar irreflexivamente valoraciones del ámbito de lo político al ámbito de la nación. Por ello, no podemos utilizar categorías pertenecientes a lo social (inclusivo-exclusivo) o a lo nacional (étnico-político o cívico) para explicar diferencias que pertenecen al campo de lo político.

Palabras clave: nacionalismo étnico, nacionalismo cívico, Cataluña, País Vasco.

\section{Abstract. Is Catalan nationalism really civic and Basque nationalism ethnic?}

One way of typifying nationalism, with regards to the type of nation one seeks, differentiates between political, territorial or civic nationalism and ethnic or cultural nationalism. Yet, nationalism, particularly in the case of stateless nations, cannot be understood if we ignore the political aspect, which does not imply interpreting it in a politicised fashion. In my opinion, such is the case with Catalan and Basque nationalism, which are presented as opposed models: the former, civic and inclusive; and the latter, ethnic and exclusive. However, their conception of the nation is quite similar, and what really separates them is political policy. The characterization of nationalism as inclusive or exclusive is thus related to its being politically radical and not to its nature as a nation. I believe that the nation and the national question have characteristics of their own, and evaluations made on politics should not be applied in a thoughtless fashion when referring only to the subject of the nation. In consequence, we cannot use categories pertaining to society (inclusive-exclusive) or to the nation (ethnic-political or civic) to explain differences pertaining to the political field.

Key words: ethnic nationalism, Civic nationalism, Catalonia, Basque Country. 


\section{Sumario}

1. Sobre los tipos de nacionalismo

2. Caracterización de los nacionalismos catalán y vasco
3. ¿Es étnico el nacionalismo vasco y cívico el catalán?

Bibliografía

La tipificación de los nacionalismos ha sido objeto de tales matizaciones en los últimos años, que hoy se hace casi imposible formular diferenciaciones absolutas entre ellos, tales como romántico / liberal; étnico-cultural / político-territorial; objetivo / subjetivo, etc. Hoy se acepta que cada nacionalismo puede contar, en cada momento histórico, con diversos grados de uno y otro de los componentes citados, por lo que las comparaciones entre ellos habrán de ser obligatoriamente relativas. Buena parte de la forma y ritmo en que el nacionalismo evolucione vendrá dada por los condicionantes políticos de cada experiencia, pues, rotundamente, el nacionalismo no puede entenderse sin su vertiente política. Se puede incluso decir que, en el caso de las naciones sin estado, a no ser que se manifieste una clara tendencia cultural en él, muchas veces lo que realmente marca la pertenencia a un nacionalismo es el apoyo político a esa opción, más allá de otras caracteristicas, más evidentes, pero que pueden desempeñar un papel más simbólico que práctico en el devenir de dicho nacionalismo. Esto suele suceder así en la primera fase, ascendente, de los nacionalismos, hasta que consiguen alguna forma de autogobierno que los satisfaga. Una vez conseguida alguna cota importante de poder, se suele tender hacia un tipo de nacionalismo político clásico.

Reconocer el carácter político del nacionalismo no significa, sin embargo, interpretarlo de manera politizada. No, al menos, si se pretende hacer un estudio lo más objetivo, y justo, posible. La nación y el tema nacional tienen unas características propias, y no podemos, por ello, trasladar irreflexivamente valoraciones del ámbito de lo político al ámbito de la nación. No se puede hacer corresponder concepciones radicales en el ámbito de lo político con concepciones radicales en el ámbito de la nación, pues son muchos los casos que nos demuestran lo contrario (políticas radicales desarrolladas por nacionalismos moderados y viceversa).

Cataluña y el País Vasco proporcionan, a mi entender, ejemplos de interpretaciones politizadas, tal vez de manera inconsciente en algún caso, y de ello resulta lo que considero el contrasentido de presentar como modelos opuestos de nacionalismo al catalán y al vasco, cuando su concepción de la nación resulta bastante similar y lo que sí los separa es la práctica política. La caracterización del nacionalismo se hace en estos casos desde este punto de vista de la práctica política, y después se traslada al ámbito de la nación. El objetivo principal de este artículo no es determinar qué tipo de nacionalismo es el catalán o el vasco, sino, sobre todo, hacer ver que la diferenciación que normalmente se hace entre ellos responde a una categorización política (radical, mode- 
rado...) y no al concepto de nación que cada uno defiende. De hacer esto último, veríamos, tal vez curiosamente, las grandes similitudes entre ambos.

Para intentar aclarar algún malentendido en torno a esta cuestión, trataré de profundizar en los tipos de nacionalismo, en general, para, tras revisar someramente las experiencias vasca y catalana, mostrar las diferencias y, sobre todo, similitudes que unen a estos dos nacionalismos.

\section{Sobre los tipos de nacionalismo}

En un plano teórico, podríamos distinguir algunas propuestas de nacionalismos no políticos, que no pretenden integrar a la población alrededor de un ideario, sino que se conforman con permanecer en un plano personal (y, por ello, las podríamos encuadrar dentro de un enfoque personal), pero no han pasado de ser propuestas, sin llegar a llevarse a la práctica. Lo que ésta última nos dice, en cambio, es que todos los nacionalismos aspiran a ejercer algún tipo de poder sobre un territorio concreto - aquél al que se ha considerado como propio de la nación- y a integrar en ese proyecto a todos aquellos habitantes de ese territorio que se considera que forman parte de la nación - lo cual no coincide siempre con la totalidad de los habitantes-. Este enfoque territorial es, sin duda, el que ha prevalecido en todos los nacionalismos. En él, se entiende que a cada nación le corresponde un espacio y, por consiguiente, a cada espacio, una nación, aparte de que, políticamente, se considere necesario o no formar un estado independiente.

Pero, a pesar de los diferentes enfoques, el nacionalismo necesita fundamentar su razón de ser; es decir, qué lo diferencia de otras naciones. Para ello, en ambos enfoques, se hace uso de dos principales tradiciones, que aquí denominaré étnico-cultural y política, y que, por lo conocido, no necesitarán de excesiva explicación.

\section{Nacionalismo político y nacionalismo étnico-cultural}

En el nacionalismo llamado politico, la nación la constituyen aquellos miembros de la sociedad que, voluntaria e individualmente, y por medio de un contrato implícito, aceptan formar un estado dentro de un determinado territorio. Individuo, territorio y voluntad son, así, las bases de este contrato teórico, y son, también, los fundamentos en los que se basa la nación política, sin necesidad de ningún otro requisito, de tipo social, étnico o cultural. El nacionalismo étnico-cultural, por su parte, niega el sentido de contrato que tenía el tipo anterior. Aquí, la nación no resulta de ninguna decisión individual y voluntaria, sino que es un hecho objetivo, del cual participan todas aquellas personas que cumplen unos determinados requisitos de tipo étnico o cultural. La pertenencia — voluntariaa un estado no puede borrar, pues, los vínculos — naturales - nacionales.

¿Cuáles son estos vínculos nacionales? A pesar de lo constante de su uso, lo cierto es que no existe total unanimidad en este aspecto. Clifford Geertz hace mención a ellos, con el nombre de primordialismo: 
Por apego primordial se entiende el que procede de los hechos «dados» —o, más precisamente, pues la cultura inevitablemente interviene en estas cuestiones, los supuestos hechos «dados»— de la existencia social: la contigüidad inmediata y las conexiones de parentesco principalmente, pero además los hechos dados que suponen el haber nacido en una particular comunidad religiosa, el hablar una determinada lengua o dialecto de una lengua y el atenerse a ciertas prácticas sociales particulares. (1987: 222)

Y, a continuación, enumera los elementos primordiales: los supuestos vínculos de sangre, la raza, la lengua, la región, la religión y las costumbres (1987: 224-225) ${ }^{1}$.

Existen otros autores, en cambio, que conceden a la lengua un sentido más político que étnico-cultural. Así, Kymlicka considera inclusivo el nacionalismo en Estados Unidos, porque está abierto:

[...] a cualquiera que viva en el territorio en la medida en que aprenda la lengua y la historia de la sociedad. Estos Estados definen la pertenencia en términos de participación en una cultura societaria común, abierta a todos, más que por razones étnicas. (1996: 11)

Trataremos más adelante este tema, pero, en cualquier caso, hoy se asume ampliamente que todos los nacionalismos incluyen características, en diversa proporción, de uno y otro tipo. Linz, incluso, señala que, al menos en Europa Occidental y especialmente en aquellas regiones que han recibido una fuerte inmigración, en la primera fase de los nacionalismos se tiende a desarrollar los vínculos primordiales, pero, en la medida en que este nacionalismo tenga éxito y necesite hacerse accesible a toda la población, tenderá a buscar lazos de unión menos estrictos, y hará uso de vínculos políticos (1985: 204)². Un ejemplo, fuera de Europa, nos lo presenta Keating en Quebec. Lo que en un principio fue identificación étnica, llamada francocanadiense, que abarcaba a todos los habitantes residentes en Canadá que cumplían aquella condición, se le ha impuesto otra más territorial, llamada ahora quebequesa, que circuscribe su influencia al Quebec y abarca a toda la población incluida en ese territorio. (1996: 92). El nacionalismo quebequés abandona su concepción étnica:

[...] para convertirse en un nacionalismo cuya base es más el territorio, si bien la lengua continúa ocupando un lugar central. (1996: 99)

1. Lo mismo dicen, posteriormente, otros muchos estudiosos del tema. Uno de los primeros, Linz: «Primordial ties have been defined as relations based on a common language, culture, distinctive religion, or kinship" (1985: 204).

2. También Letamendia hace referencia a este proceso. Según él, con el tiempo, el movimiento se institucionaliza y adopta una "lógica instrumental-racional», aunque no deje de mantener una dimensión ideológico-identitaria, la cual será más o menos empleada, en función del éxito político que se obtenga (1997: 111). 
Esto sucede así porque el nacionalismo quebequés se ha convertido en hegemónico. Es importante entender esta unión entre ambos tipos de nacionalismo: la práctica política lleva a prioritar los vínculos políticos sobre los primordiales, pero ello no quiere decir que éstos últimos desaparezcan. $\mathrm{Al}$ contrario, normalmente siguen muy presentes en el imaginario nacionalista, cumpliendo un claro papel simbólico, como referente afectivo principal del nacionalista.

Esto no significa, desde luego, que no podamos hacer diferencias entre nacionalismos, pero debemos extremar las precauciones a la hora de identificarlos con algún tipo concreto. Una forma de distinguirlos, a juicio también de diversos estudiosos del tema, es el carácter incluyente o excluyente del nacionalismo para con la población del territorio que se reivindica. El nacionalismo étnico-cultural es exclusivo con respecto a quienes no cumplen las características primordiales fijadas para su nación, mientras que el nacionalismo político o cívico se entiende que es inclusivo, pues en él cabe toda la población de un determinado territorio. Es el tipo de nacionalismo que han desarrollado numerosos estados nación, en los cuales se iguala nación y ciudadanía, pues, por su carácter inclusivo, considera que todos sus ciudadanos constituyen una única nación. Conviene diferenciar ambos conceptos de nación y ciudadanía, por dos razones. Primera, porque se puede dar a entender que el nacionalismo busca la división de su propia nación, lo que, desde luego, no es cierto. El nacionalismo busca siempre la integración de lo que ha considerado su nación, pero si ésta no se basa en un criterio político, no incluirá al total de la población del territorio reivindicado por el nacionalismo. Segunda, porque se puede dar a entender que el nacionalismo discrimina a los que no forman la nación étnica. Esto, que muchas veces es verdad, no lo es siempre, ya que los derechos administrativos de ciudadano pueden no ser negados: en un estado multinacional las naciones se excluyen, pero los derechos administrativos son universales.

En cualquier caso, Kymlicka aclara convenientemente que ambos tipos de nacionalismo:

[...] suponen la politización de los grupos etnoculturales. Ambos construyen la pertenencia nacional en cuanto participación en una cultura societaria común, y ambos emplean las políticas públicas para mantener y perpetuar esa cultura societaria. (1996: 11)

El carácter político del nacionalismo, en cualquiera de sus concepciones, es, precisamente, una de sus claves, muchas veces difuminada en las discusiones sobre otras características. Este carácter político ya lo señala Fichte. Éste, recogiendo el legado etnicista de Herder, reconoce el papel principal de la lengua en la nación alemana, pero no lo considera suficiente, pues, para poder asegurar el futuro de esa lengua, es necesario que exista una autonomía política; sin ella, sería imposible el desarrollo de la nación alemana (1988: 214). El componente político de la nación acaba, finalmente, prevaleciendo: 
[...] Todo aquel que cree en la espiritualidad y en la libertad de esta espiritualidad y desee su desarrollo eterno dentro de la libertad, no importa donde haya nacido ni en qué idioma hable, es de nuestra raza, nos pertenece y se unirá a nosotros. El que cree en el estancamiento, el retroceso, la danza circular o sencillamente pone al timón del gobierno del mundo una naturaleza muerta, donde quiera que haya nacido y hable el idioma que hable, no es alemán, es extraño a nosotros, y es de desear que se separe de nosotros por completo y cuanto antes mejor. (Fichte, 1988: 131)

\section{El nacionalismo en las naciones sin estado}

La importancia de este factor político, que acabamos de ver, se refleja especialmente en los nacionalismos sin estado, que es el caso que aquí nos ocupa, pues todo nacionalismo está orientado a alcanzar alguna cota de poder, para poner en marcha su proyecto de nación. En este afán, todo aquél que no se identifica con dicho proyecto se convierte, objetivamente, en un obstáculo, pero un obstáculo político y objetivo; es decir, motivado por un problema concreto y de carácter transitorio. Así es que, una vez superado el problema, el nacionalismo que alcanza sus objetivos desvelará realmente su proyecto inclusivo o exclusivo de nación, al igual que otros nacionalismos con estado constituido: aquellos partidarios de una nación política incluirán a todos los habitantes del territorio; y los partidarios de la nación étnico-cultural discriminarán, en mayor o menor medida, a los habitantes que no cumplan los requisitos nacionales. Por tanto, en los nacionalismos sin estado, el compromiso político por el proyecto que dicho nacionalismo emergente propone se convierte en un vínculo más para sus partidarios. Es la voluntad de crear una nación la que, entre otros aspectos, los une.

Esta voluntad choca, sin embargo, con el proyecto nacional del estado ya constituido. Éstos, en Occidente al menos, optan normalmente por desarrollar formas de nacionalismo político-territorial que, precisamente por su carácter inclusivo y, a primera vista, democrático, suponen la negación del nacionalismo de la nación sin estado. Efectivamente, el nacionalismo político tiene por virtud no excluir a ningún ciudadano del territorio, pero, por defecto, incluir, aún a la fuerza, a todos ellos, y esto choca con aquellos ciudadanos que, por influjo de otro nacionalismo, no se identifican con el estado. Éste confunde, voluntariamente y con el fin de homogeneizar —o no discriminar - a la población, el concepto administrativo de ciudadanía con el de nación, y extiende la nacionalidad a todo aquel ciudadano con derecho a serlo. Lo que en un principio era unión voluntaria, acaba negando la voluntad de algunos ciudadanos que no se sienten parte del estado. Como señala A. D. Smith, en nombre de la

3. Según Renaut, representa un primer intento de superar la contradicción existente entre las definiciones étnico-cultural y político-territorial de la nación. Fichte propone otra lógica, «no de simple y pura adhesión, ni de simple y pura pertenencia, sino de educabilidad». Es decir, el individuo elige por propia voluntad su comunidad, y al aceptarla se integra en esa cultura y esa tradición. Une, así, voluntad y tradición (1993: 59-60). 
igualdad se legitima la imposición: a cambio del derecho de ciudadanía, la minoria étnica pierde su identidad colectiva, para asimilarse en el nuevo colectivo de rango superior (1994: 16). Vistas las experiencias que han seguido este tipo de nacionalismo:

[...] veremos cuán rígida y exclusivista es la concepción cívica de la nación, y lo mucho que puede pesar sobre la vida cultural y social de las minorías. (Ibídem: 1994: 17)

El carácter inclusivo o exclusivo del nacionalismo debe ser, pues, convenientemente matizado ${ }^{4}$.

Finalmente, merece también alguna matización el término cívico usado con relación al nacionalismo. Nacionalismo civico es sinónimo de político o territorial; es decir, aquel nacionalismo que basa la nación en el territorio y en la voluntad de sus habitantes, y no en elementos étnicos o culturales. Sin embargo, creo que el término cívico conduce a veces a equivocaciones, al concederle una dimensión político-ideológica que no es esencial al concepto de nación, sino complementaria. Es decir, por nacionalismo cívico se quiere, a veces, significar un tipo de nacionalismo que desarrolle una práctica política democrática moderada, y no radical, en su planteamiento nacionalista; que no cree divisiones en la sociedad. Ahora bien, esta división, si existe, lo es en el plano político — como podría aparecer entre ideologías diferentes-, y no en el plano nacional: la quiebra, por ejemplo, se produce entre independentistas y autonomistas, o separatistas y lealistas, pero no indica, obligatoriamente, que alguien sea excluido de la nación. La identificación entre nacionalismo cívico o político con democrático me parece una relación peligrosa y que, históricamente, no se cumple 5 . Volveremos al tema en el tercer apartado.

\section{Caracterización de los nacionalismos catalán y vasco}

Todo lo expuesto lo pondremos, a continuación, en relación con los nacionalismos catalán y vasco. Ambos surgen a finales del siglo XIX, en una época de auge del nacionalismo, y en un contexto de desarrollo capitalista y de modernización del estado. El primero de ellos suele ser presentado como modelo de la varie-

4. El carácter inclusivo del nacionalismo cívico podría chocar también con nuevas teorizaciones sobre el nacionalismo, menos politizadas que las clásicas, en las que se tiende a separar los conceptos de nación y ciudadanía. Aquí, la nación no se identificaría con el estado, por lo que podría volver a tener un carácter étnico-cultural y exclusivo, pero sin resultar traumático ni lesivo para otros intereses, pues se supone que la población tendría unos derechos de ciudadanía comunes, y después se agruparía en sus naciones correspondientes, cada una de las cuales atendería a una característica étnica o cultural.

5. Un ejemplo podría ser la dictadura de Franco, bajo cuyo mando España desarrolló un tipo de nacionalismo claramente político-territorial, sin que, desde luego, pueda añadírsele la categoría de democrático. 
dad político-territorial, y el vasco, en cambio, de la modalidad étnico-cultural, pero existen más opiniones.

\section{El nacionalismo catalán}

La lengua es tenida por uno de los principales aglutinantes del nacionalismo catalán desde sus comienzos, aunque no haya sido la única formulación posible, como veremos. Está en Prat de la Riba, quien, influenciado por el romanticismo alemán, basa su nacionalismo en la lengua, e iguala lengua y nación, pero no, por ejemplo, en una de las figuras señeras del primer nacionalismo, Almirall, que no la consideraba como el factor principal de la nación. Sin embargo, la postura dominante, y con el tiempo cada vez menos puesta en duda, es que Cataluña forma una nación porque tiene una lengua propia. Esta asunción de la lengua como distintivo cultural propio excede al nacionalismo y es ampliamente asumida por gran parte de la población catalana, al contrario de lo que sucede en la sociedad vasca, donde el grado de politización alrededor de la lengua es mayor.

Sin embargo, y aun reconociendo el papel preeminente de la lengua, existen, como es lógico, otras diferentes concepciones de la nación. Desde sus orígenes hasta nuestros días, Colomer (1986) da cuenta de un nacionalismo racial, aunque muy minoritario, a comienzos del siglo XX. Un nacionalismo liberal, basado en la voluntad, en la conciencia, lo aporta, por ejemplo, Antoni Rovira i Virgili, Francesc Macià o Carles Pi i Sunyer. Es el nacionalismo republicano, de ERC, en general. Un nacionalismo objetivo y socialista, basado en las condiciones de Stalin para la existencia de una nación, lo propone Andreu Nin o Joan Comorera. Otro nacionalismo esencialista, basado en la lengua, e independentista, es el de Josep M. Batista Roca (en su vertiente liberal), o Josep Ferrer, Carles Castellanos, o el PSAN, en general (en su vertiente socialista). Finalmente, sobresale también un último nacionalismo objetivo e integrador, basado en la lengua y en el territorio, pero donde éste segundo actúa como principio, de forma que no discrimina a los inmigrados, aunque la lengua sea el verdadero centro de la catalanidad, como en Francisco Candel, Jordi Pujol o Antoni M. Badia Margarit.

Si bien la lengua suele entrar en la categoría de factores primordiales, tal como decíamos en el capítulo anterior, no sucede así en el caso catalán, donde se señala, precisamente, su papel integrador (Conversi, 1997: 185; Termes, 1984). En general, la mayoría de los estudiosos del tema coinciden también en conceder un carácter cívico e inclusivo a este nacionalismo. Así lo hacen Daniele Conversi (1997), Michael Keating (1996), aunque siga percibiendo una dimensión étnica fuerte, Joan-Lluís Marfany (1995), que señala a la voluntad como eje de la nación catalana, o Araceli Serrano (1998).

\section{El nacionalismo vasco}

En el nacionalismo vasco se promociona la lengua, pero aquí no alcanza a tener el carácter aglutinante que sí logra en el nacionalismo catalán. La razón es, evi- 
dentemente, que la lengua vasca no tiene el grado de expansión que alcanza el catalán. Es por eso que el primer nacionalismo vasco busca en la etnia y la raza el principal factor cohesionante de la nación vasca, y no será hasta la década de 1950 cuando el nuevo símbolo principal de la nación vasca pase a ser la lengua.

En el nacionalismo vasco existen, pues, varias propuestas teóricas sobre el fundamento de la nación vasca. Resumidamente, y en el tiempo, se pueden diferenciar las siguientes (v. Zabalo, 1998): primeramente aparece un nacionalismo racial, de la mano de su fundador, Sabino Arana. Ante las dificultades prácticas que este planteamiento conllevaba, pronto comienza a desarrollarse un nacionalismo racial-territorial, en el cual la raza sigue ocupando, en un plano simbólico, el papel preponderante como elemento constitutivo de la nación vasca, pero, en la práctica, queda muchas veces desbordado por un planteamiento más político ${ }^{6}$. La superación de la raza, en la teoría o en la práctica, como eje vertebrador de la nación comienza a concretarse en la década de 1950, de la mano, sobre todo, aunque no exclusivamente, de la izquierda del nacionalismo. El énfasis se pone ahora en la lengua, a pesar de lo cual nunca ha llegado a existir lo que pudiéramos llamar un «nacionalismo lingüístico» (como hubo uno racial), y sí, en cambio, una variedad lingüístico-territorial, en la cual, al igual que en la anterior racial-territorial, la lengua ocupa simbólicamente el centro de la nación vasca, pero, a la hora de la práctica, se impone muchas veces la realidad social, y se opta por soluciones de tipo político. A estas principales propuestas que se han dado en el nacionalismo vasco, podríamos añadir, finalmente, una variedad puramente territorial, formulada de modo aislado y sin el apoyo, aún, de ninguna fuerza política. En cualquier caso, hoy en día, la opción lingüístico-territorial sigue siendo la predominante en el nacionalismo vasco.

Así como veíamos bastante coincidencia en adjudicar un carácter cívico e inclusivo al nacionalismo catalán, existen más dudas para caracterizar el nacionalismo vasco, aunque lo más común y clásico es calificarlo de étnico y exclusivo (Termes, 1984: 186; Etxeberria, 1998: 44; Serrano, 1998: 100-1017). Conversi, por su parte, matiza su posición, sin llegar a pronunciarse totalmente sobre el tema: el nacionalismo vasco fue exclusivo en su principio, pero el actual pone su énfasis en la lengua, aunque, para él, no ha llegado a constituirse en el eje de la nación. El nacionalismo vasco no cuenta, en realidad, con un elemento central para definir la nación (1997: 186). Cuando llega a definirlo, en cambio, lo hace con la contradictoria fórmula de exclusivo y político, donde se supone que político significa 'politizado', y no se refiere, por tanto, a la concepción de la nación, étnica o política. Quien sí señala, sin embargo, perfectamente el carácter político del nacionalismo vasco es Jeremy MacClancy, para quien:

6. Esta evolución, muchas veces olvidada, es convenientemente recogida por Beobide (1993) y Fusi (1984: 197; 221).

7. Pero advierte que en el momento en que se realizó la investigación, años 1986-1987, había comenzado una transición hacia un nacionalismo cívico-territorial (Serrano, 1998: 101). 
Basque patriots are abertzales, a status not defined by birth but by performance: an abertzale is one who actively participates in the political struggle for an independent Basque nation with its own distinctive culture. You are not born abertzale. You make yourself one. [...] To abertzales, Basques are those who live and sell their labour in Basqueland. (1988: 17)

Santiago, finalmente, también admite claramente que el nacionalismo vasco, como el quebequés, se aleja del etnicismo, y el territorio se convierte en el elemento central de la definición de nación vasca $(2001: 165-167)^{8}$.

\section{3. ¿Es étnico el nacionalismo vasco y cívico el catalán?}

Volvamos ahora a la comparación entre los nacionalismos catalán y vasco. ¿En qué se diferencian, teóricamente, ambos nacionalismos, y cuáles son las características cívico-territoriales que no cumple el nacionalismo vasco? Creo que ninguna, y que podríamos equiparar, en este punto, ambos nacionalismos. Sin embargo, parece claro que existe una opinión generalizada que los contrapone a ambos. Como hemos dicho, el nacionalismo vasco es frecuentemente calificado de étnico y exclusivo, además de político o politizado; el nacionalismo catalán, en cambio, sería cívico e inclusivo, además de ser ampliamente calificado de lingüístico. ¿Pero qué significan estas caracterizaciones de lingüístico y político?

En cuanto al factor lingüístico, una primera cuestión debería ser, desde luego, dilucidar si la lengua es considerada como un factor esencial de la nación o no; si es un elemento integrador e inclusivo o no. Por lo que se deduce de diversas opiniones y estudios sobre este apartado, parece que lo que hay que entender es que caracterizaremos a la lengua como elemento integrador cuando su aprendizaje facilite, precisamente, que el individuo ajeno a una determinada comunidad o a un determinado territorio se incorpore (sin más problema o presión que la personal al dejar su país original) a este nuevo medio. El mayor uso del catalán lo haría más integrador que el euskera, pero en ambos casos tenemos una lengua de mayor uso, el castellano o el francés. ¿Por qué, entonces, habría de ser más integrador el nacionalismo catalán que el vasco por medio de su lengua? De hecho, el conflicto entre lenguas es más patente en Cataluña, por la mayor fuerza del catalán ${ }^{9}$, y nada hace pensar, sino todo lo contrario, que el nacionalismo catalán busque alguna forma de equilibrio con el castellano. Andrés Barrera plantea abiertamente que el nacionalismo catalán busca extender la lengua catalana, de forma que se pueda hacer patente la diferencialidad nacional (1997: 136).

Si el problema fuera el conflicto entre lenguas, el éuskara, menos utilizado que el catalán, tendría que representar un problema menor. Sin embargo, ya hemos visto que es en este caso cuando se habla de la lengua como factor

8. Y, a continuación, señala alguna inconsistencia existente en tal planteamiento.

9. Para Barrera, el catalán se ha convertido «en una de las armas dialécticas favoritas en la pugna entre los diversos actores del espectro político» (1997: 109). 
excluyente. Más bien parece que la dilucidación sobre la capacidad exclusiva o inclusiva de la lengua depende de su fuerza y vitalidad social. Ésa es la razón de que aprender inglés en Estados Unidos sea un elemento integrador y, a partir de ahí, que su nacionalismo sea denominado «inclusivo». Es decir, la caracterización de la lengua, con respecto a la nación, de inclusiva o exclusiva es una cuestión política, que depende del formulante.

Sobre el factor político, debemos saber si, al caracterizar así a un nacionalismo, estamos nombrando un tipo de nacionalismo, o estamos afirmando que un determinado nacionalismo está politizado. Dentro de la categorización general del nacionalismo vasco como étnico-cultural, Xabier Etxeberria dice que, el de ETA, «evidentemente no es un nacionalismo cívico» (1998: 34), y que el nacionalismo de la izquierda abertzale es totalitario; no acepta el nacionalismo cívico (ibídem, 1998: 54 y 55). Ahora bien, el opuesto de nacionalismo cívico es étnico, y totalitario no es una categoría de nacionalismo, sino de práctica política.

Por otra parte, es norma entender que el nacionalismo étnico-cultural nunca puede tener un carácter democrático, mientras que otros son más aceptados en ese ámbito, como el cívico o político. Sin embargo, considero que el concepto de democracia es mejor segregarlo del de nación. El nacionalismo es un movimiento social con clara vocación política, por lo que su actuación va unida a conceptos políticos. Así, un nacionalismo podrá ser democrático o no, pero ello corresponderá simplemente a la unión de dos características (nación y democracia) y no a que exista una única esencia. Es decir, el nacionalismo no es, por sí, democrático o no, sino que esto último es una categoría añadida. El nacionalismo afecta al concepto de nación, y su intento de promoción de ella. Además de esto, como movimiento político que es, optará por unas determinadas posturas que definan su ideología y fijen su posicionamiento político. Será, así, socialista o democráta-cristiano; se posicionará en los grandes temas actuales, como ecología, mujer, juventud, etc. Dentro de este ámbito es donde debe situarse la disyuntiva demócrata / no demócrata, pero sin afectar por ello al concepto central del nacionalismo: la nación. Realizar la diferenciación demócrata / no demócrata no carece de sentido, pero no debería presentarse como una característica intrínseca a unos tipos de nacionalismo.

De la misma forma, tampoco parece cierta la relación que se hace entre nacionalismo político o cívico y estabilidad política, por un lado, y nacionalismo étnico e inestabilidad política, por otro. A. D. Smith da ejemplos evidentes de ello: el nacionalismo del País Vasco, a su parecer, es étnico e inestable políticamente, pero también son inestables los nacionalismos cívicos de España, Canadá, Francia o Bélgica. Y, por el contrario, según él, existen nacionalismos étnicos que son estables políticamente, como el catalán (1994: 16).

\section{Prejuicios sobre los nacionalismos catalán y vasco}

Sobre los nacionalismos catalán y vasco existe más de un prejuicio, que comienzan a la hora misma de estudiarlos, ya que sus centros de interés varían para 
los estudiosos según el caso, por mucho que en gran cantidad de aspectos tanto las condiciones generales como las respuestas de cada nacionalismo no parezcan diferir demasiado ${ }^{10}$. Pero en ambos se aprecia la necesidad de actuar en un triple frente: el cultural, especialmente en lo referente a la lengua, el social, sobre todo en la necesidad de atraer hacia el nacionalismo a las constantes oleadas de inmigrantes que van llegando, y el político, con un primer objetivo de luchar por unas condiciones democráticas. Sin embargo, en numerosos estudios, al tratar el nacionalismo catalán se habla de la lengua, de la necesaria integracion de los inmigrantes, etc. En el País Vasco, en cambio, se habla sobre todo de la actividad política y de la violencia unida a ella en algunos casos. Veamos todo esto en tres aspectos: la definición de la nación, la lengua y la inmigración.

En el primer aspecto, y tras la guerra, los dos llegan a formular una nueva definición de lo que es ser catalán o vasco, realmente similares, a pesar de que sean expuestas por gente tan diferente como Jordi Pujol o ETA. En estos años se realizan claras definiciones voluntaristas de lo que sería el fundamento de la nación: vasco o catalán sería todo aquél que viviera y tuviera voluntad de vivir en el País Vasco o Cataluña. Así, ya en 1958, Jordi Pujol decía que:

Català ès tot home que viu i treballa a Catalunya, i que amb el seu treball, amb el seu esforç, ajuda a fer Catalunya ${ }^{11}$.

Y, por su parte, ETA proponía:

[...] un independentismo basado en el concepto de "pueblo trabajador vasco", un concepto que hacía de la clase trabajadora vasca e inmigrante el fundamento de la nacionalidad. (Fusi, 1984: 211)

Esta definición suele servir en el caso catalán para que se le incluya en la categoría de cívico-territorial. Para Araceli Serrano, por ejemplo, el nacionalismo catalán se acerca a ese tipo de nacionalismo:

Catalán será todo aqu[é]l que vive y trabaja en Cataluña, abundando en la dimensión cívico-territorial y el carácter inclusivo e integrador del nacionalismo catalán (1998: 109).

Pero no sucede lo mismo con el vasco, a pesar de que incluso podría demostrar mayor voluntad integradora, según algunos estudios, como el ya comentado de Linz sobre cuál es el soporte de la nación para los vascos y catalanes. Conversi lo señala claramente, cuando dice que, a partir de la década de 1960,

10. Así lo señala también Díez Medrano: «[...] en los estudios sobre nacionalismo vasco existe la tendencia a centrarse exclusivamente en ETA, en los trabajos sobre nacionalismo catalán se tien[d]e a hacer excesivo hincapié en la movilización burguesa» (1999: 190, nota 2).

11. Jordi Pujol, escritos de 1958, recogidos en 1976 en su libro La inmigració, problema i esperança de Catalunya (en Termes, 1984: 155). 
tanto el nacionalismo catalán como el vasco intentaron integrar a los inmigrantes. El primero lo hizo por medio de la cultura: el dominio de la lengua facilitaba la integración; el segundo lo hizo por medio de la participación política, en nombre de la solidaridad de clase (1997: 220). Paradójicamente, sin embargo, el nacionalismo vasco es exclusivo cuando sólo exige compromiso político, y el catalán inclusivo cuando exige el conocimiento de la lengua a los que no la saben.

Sobre la lengua no se dice demasiado en el caso vasco y, cuando se menciona, no se le concede la importancia que se le da en Cataluña ni se valora la enorme actividad desplegada en la recuperación del éuscara o en otras expresiones culturales vascas. Para Araceli Serrano, en ambos casos la lengua marca el hecho diferencial, pero considera que en Cataluña juega un papel más positivo que en el vasco, pues aquí es usada "como arma política arrojadiza» (1998: 113). En parecidos términos se expresa Daniele Conversi, al señalar que la lengua resultaba un eficaz instrumento para remarcar las diferencias étnicas, por lo que el nacionalismo lo convirtió en uno de los fundamentos de la identidad vasca, pero sin tener el papel movilizador que tuvo en Cataluña (1997: 124-125). Marianne Heiberg reconoce que la lengua y la cultura se han convertido en los símbolos del nuevo nacionalismo vasco, pero ello no supone un avance con respecto a las posiciones del primer nacionalismo, pues la lengua cumple la misma función política que cumplía la raza: la diferenciación sobre lo no vasco (1991: 162-163). Barbara Loyer, finalmente, destaca la radicalidad vasca en la defensa de la lengua:

De nombreux Basques sont donc convaincus que seule une position intransigeante en particulier sur la question de la connaissance obligatoire de la langue [...] dans l'administration ou l'enseignement, évitera la disparition de leur culture, donc du peuple basque (1990: 49),

lo que contrasta vivamente con las constantes referencias de moderación que la autora hace al tratar Cataluña, donde en absoluto se habla de radicalidad en el tema lingüístico, a pesar de su evidencia, y ello porque previamente se ha concedido mayor importancia al posicionamiento político.

Para terminar, en el tema de la inmigración, se ensalza muchas veces el esfuerzo catalán, y se silencia el vasco. Sin embargo, dice Juan Pablo Fusi que en el País Vasco no se puede hacer una diferenciación cerrada entre autóctonos e inmigrantes, porque se han alcanzado altas cotas de integración (1984: 253). Y Díez Medrano, por otra parte, aporta unos datos, bastante parecidos, pero favorables al País Vasco, sobre el grado de aceptación de los inmigrados en ambas regiones: en Cataluña, un 19,1\% se mostraba a favor o muy a favor de que volvieran a sus sitios de origen; en la Comunidad Autónoma Vasca, lo era sólo el $10,3 \%{ }^{12}$.

12. Estudio realizado en 1988 por Análisis Sociológicos, Económicos y Políticos, y recogidos en Diez Medrano (1999: 223, tabla 25). 
Parece, sin embargo, como si estos temas y aspectos no cuadraran en el esquema preconcebido de un nacionalismo vasco más preocupado por la política que por la cultura, más preocupado por el mantenimiento de la raza vasca que por la integración de los no originarios. De ahí surgen después los frecuentes titubeos y contradicciones que abundan en los enjuiciamientos sobre este nacionalismo: un nacionalismo racista que, sin embargo, acepta (incluso en mayor proporción que el catalán con sus inmigrantes) el carácter vasco de los no nacidos en Euskal Herria; un nacionalismo violento y excluyente donde abundan los militantes nacidos fuera, que se suponía que eran los excluidos, etc.

\section{Nacionalismos estereotipados: conceptos sociales para problemas politicos}

Una diferencia evidente entre los dos nacionalismos creo que nos puede dar una buena pista para entender su encasillamiento: el nacionalismo vasco tiene una vertiente más política que el catalán, y éste, una más cultural que aquél. El nacionalismo catalán de la década de 1960 evita muchas veces pronunciarse sobre sus objetivos políticos con respecto a España; evita, por lo general, declararse separatista ${ }^{13}$. Mantiene, en cambio, un proyecto político ambiguo, compatible con diversas formas de estructuración política, ya que lo importante, en palabras de Colomer haciendo referencia a Pujol, es la esencia. Dentro de esa ambigüedad, también la autonomía tiene cabida (1986: 188). Para Pujol, Cataluña es una nación incluida en España (1993: 83), y que no tiene intención de separarse, sino que, por el contrario, se muestra muy activa en la política española (ibídem: 130). El mensaje del PNV de los años sesenta es también ambiguo, además de casi inexistente, pero es, en cambio, muy claro el de ETA. ¿Esta claridad en los objetivos políticos explicaría el carácter cívico del nacionalismo catalán; es decir, su carácter no radical?

Cuando se habla de radical en política, se suele hacer referencia normalmente a posiciones de izquierda y/o a posicionamientos rotundos y difícilmente rebajables en los objetivos a conseguir. Por ello, el nacionalismo radical suele ir normalmente unido a concepciones de izquierda. Así sucede, sin duda, en los años sesenta y setenta en el Estado español, cuando se desarrolla con fuerza un nuevo nacionalismo en Galicia, Cataluña y País Vasco. Como expone Rubiralta (1997), sus dos características principales son la radicalidad política y la recuperación del etnismo, en especial alrededor de la lengua. La radicalidad política no se limita a concepciones revolucionarias de izquierda en lo social, sino también en lo nacional:

[...] la reivindicación de la independencia será una de las banderas preferidas del nuevo nacionalismo y, en general, nos encontraremos ante [...] un discurso poco abierto al pactismo, el posibilismo y a las posturas moderadas en el terreno nacionalista. (1997: 285)

13. Con la evidente excepción del nacionalismo radical de estos años, constituido sobre todo alrededor del PSAN (v. Rubiralta, 1997). 
Pero de estas tres experiencias, sólo la vasca consiguió desarrollarse plenamente, y de aquí se podría desprender una de las claves de las diferencias entre el nacionalismo vasco y el catalán: que el primero cuenta con una poderosa corriente de izquierda desde los años sesenta, y el segundo, en mucha menor medida $^{14}$.

¿La falta de un nacionalismo de izquierda explica la falta de un nacionalismo radical en Cataluña? Pero, si así fuera, si izquierda y radicalismo fueran de la mano, ¿por qué se habla siempre de nacionalismo vasco radical, cuando el nacionalismo mayoritario es el moderado del Partido Nacionalista Vasco? Son muchos los estudios que olvidan el nacionalismo vasco autonomista, siendo, paradójicamente, más importante, en ocasiones, que el independentista. No lo es en la década de los sesenta, pero pervive hasta las primeras elecciones de 1977, y, a partir de éstas, comienza a aparecer con mas peso que el nacionalismo de izquierda. ¿Por qué sucede esto? ¿Qué es moderado y qué es radical; qué es excluyente y qué es incluyente?

Una de las conclusiones de Conversi parece ser que el nacionalismo vasco no es integrador por su carácter separatista. Eso parece deducirse cuando, al compararlo con el catalán, dice que:

Catalan nationalism was at the same time organicist and integrationist, while Basque nationalism was voluntarist and separatist. (1997: 240)

Resulta curiosa la diferenciación, pues se dice que el nacionalismo catalán es organicista e integracionista y, a la vez, se ha afirmado, en sentido positivo, que es incluyente. Del vasco, en cambio, se dice que es voluntarista, además de separatista, pero, en sentido negativo, se ha dicho que es excluyente. Vista la argumentación de muchos estudiosos del tema, parece que los términos incluyente o excluyente se refieren a conceptos políticos, pero para ello utilizan una terminología referente a lo social, totalmente contraproducente. Es decir, del nacionalismo vasco se dice que es excluyente, en general, porque es separatista (aunque sea una afirmación que necesitaría de muchas matizaciones) en lo referente al campo político. Sin embargo, el nacionalismo catalán, que basa su concepto de nación en la lengua y que integraría, por tanto, sólo a quienes la aprenden, es integrador e inclusivo. ¿No lo sería más el vasco, que basa su concepto de nación en la voluntariedad y la territorialidad? El nacionalismo vasco tiene, qué duda cabe, una innegable carga excluyente en sus orígenes, pero se desprende de ella a mediados del siglo Xx. Lo que queda después es pugna política entre un nacionalismo de estado y uno periférico. El catalán, en cambio, hace ostentación de su exclusivismo lingüístico, pero rehuye, normalmente, la confrontación política total con el estado. De ahí su pretendido integracionismo. Creo que A. D. Smith es consciente de esta diferenciación política, y no relativa al campo de la nación, cuando señala que ambos nacionalismos, vasco

14. Carles Bonet dice que el nacionalismo de izquierda terminó con la guerra, y que el actual, representado por ERC, tiene una fuerza limitada (1997). 
y catalán, son étnicos, pero el primero es políticamente inestable, mientras que "difícilmente podríamos calificar los nacionalismos étnicos de catalanes, finlandeses y checos como "patológicos" o peligrosos» (1994: 16).

Pero si de integrar en la nación se trata, parece que el nacionalismo vasco es más integrador que el catalán, pues en aquél el factor de la voluntariedad pesa más, en la práctica, que cualquier otro; mientras que en el catalán es el factor lingüístico el que predomina ${ }^{15}$. Tal vez, podríamos emplear los términos de transigente e intransigente (también usados con cierta frecuencia) para definir mejor a ambos nacionalismos. Estos términos me parecen más apropiados para explicar un problema de carácter político. Así, el nacionalismo vasco sería, relativamente, más intransigente que el catalán, pues se conforma peor que éste con los grados de autonomía que el Estado le concede. Esto no tiene por qué querer decir que el nacionalismo catalán acepta para siempre estos pasos autonómicos, pero transige más fácilmente, en algunos casos porque, tal vez, le parezcan suficientes; y, en otros, porque aguardan con paciencia el momento de dar otro paso adelante.

\section{¿Nacionalismo político o nacionalismo y politica?}

Los nacionalismos buscan la defensa, compactación o promoción de una determinada nación, por lo que considero que la forma básica de distinguirlos y clasificarlos debería atender a las diferencias en la forma de entender esa nación, y posteriormente, se podrían añadir otras matizaciones, pero que no serían ya intrínsecas al nacionalismo en sí, como he dicho. A pesar de que puede haber alguna tendencia que relacione tipos de nacionalismo con otros posicionamientos políticos o sociales, no veo razón por la que el nacionalismo no pueda adoptar cualquiera de esos posicionamientos posibles, más si tenemos en cuenta la frecuente combinación de características cívico-territoriales y étnico-culturales que acostumbran a utilizar casi todos los nacionalismos. Como tantas veces se ha dicho, y tantas más se le ha negado, el nacionalismo debe ser entendido en clave política, pleno de lógica y racionalidad. Precisamente, el no querer reconocer este carácter político creo que es uno de los principales causantes de las desconcertantes propuestas que muchas veces se realizan. La caracterización de incluyente o excluyente del nacionalismo está, así, unida a su radicalidad política y no, como en un principio parecería, al carácter incluyente o excluyente de la nación que el nacionalismo propone.

Por otra parte, la definición voluntarista de la nación no puede ser entendida de la misma forma en los nacionalismos de estado que en los nacionalismos sin estado. En este último caso, se debe conceder un sentido más fuerte al término voluntad, para adquirir un significado próximo al de compromiso político. Es decir, al igual que en unos casos se utiliza la lengua o la religión

15. Sobre éstos, Linz avisaba hace bastantes años, en su hipótesis de que los nacionalismos evolucionan de su variedad primordial a la político-territorial, que el País Vasco cumple plenamente su hipótesis, y parcialmente, Cataluña y Galicia (1985: 205). 
como aglutinante de la nación, en otros sólo se pide que el individuo tome una posición política pro-nacionalista. Esto, sin embargo, es considerado como nacionalismo exclusivo, pues deja fuera - excluye - a aquéllos que no aceptan ese compromiso político. No me parece acertada esta postura, como he venido repitiendo, ya que el compromiso se exige en el campo político y no en el estrictamente nacional. Hay que tener en cuenta que la confrontación política origina profundos enconos, especialmente en el caso de un nacionalismo sin estado. No existe tanto problema en los nacionalismos con estado, pues en ellos no hay porqué exigir un compromiso político a sus habitantes. No existe incluso ningún acto de voluntariedad explícita en la adopción de la nacionalidad: simplemente se concede a todos los ciudadanos, en el sentido de nacionalidad administrativa. En los nacionalismos sin estado, en cambio, la voluntariedad es a la vez compromiso político para construir una nación que aún está por reconocer internacionalmente. Y es este compromiso político el que origina posteriormente conflictos con aquéllos que no aceptan la nación emergente. Conflicto político, como vemos, que exige, por tanto, una terminología política y no social (exclusión-inclusión en la sociedad) para comprenderlo convenientemente.

Dice Geertz que estos conflictos adquieren una dimensión especial, pues en los demás no se pone en duda la integridad política del marco, no se socava, al menos voluntariamente, la nación (1987: 223). El nacionalismo, en cambio, exige un nuevo marco de relación; una nueva demarcación territorial, lo que hace difícil a veces el acuerdo con el estado central. La radicalidad en la reivindicación nacional no debiera confundirse con civismo o con democracia, pues responden a cuestiones diferentes; no van unidos. Si hablamos de nacionalismos cívicos, políticos o territoriales —empleados como sinónimos-, habríamos de entender que dicho nacionalismo considera que la nación la forman aquellos habitantes que residen dentro de los límites que se ha tomado por nación. Otra cuestión será la forma en que este nacionalismo pretenda conseguir sus objetivos.

En el nacionalismo vasco actual, y desde hace medio siglo, se cruzan, especialmente, dos tipos de definición de la nación: la que la basa en la lengua; y la que lo hace en el territorio ${ }^{16}$. En cualquier caso, diversos estudios vienen a demostrar que el principal elemento aglutinante, en la práctica, de la nación vasca es la voluntad: es vasco quien reside en el País Vasco. El nacionalismo vasco desea incluir a todos los habitantes del territorio vasco en una única nación vasca; sin excluir a nadie (independientemente, claro, del grado de aceptación de esta propuesta). Parecida definición podríamos hacer del nacionalismo catalán, aunque aquí el factor lingüístico toma mayor relevancia, mientras que el político predomina en el vasco. ¿Podemos diferenciar, entonces, un nacionalismo catalán cívico e inclusivo de un nacionalismo vasco étnico y

16. Por esta razón, considero más ajustado denominar a este nacionalismo, predominante en los últimos años, como lingüístico-territorial (v. Zabalo, 1998). 
exclusivo? ¿Los separa su grado de exclusividad e inclusividad, o su grado de politización? Considero que esto último, pero, en ese caso, no podemos, como he repetido, utilizar categorías pertenecientes a lo social (inclusivo-exclusivo) o a lo nacional (étnico-político o cívico) para explicar estas diferencias que pertenecen al campo de lo político.

\section{Bibliografía}

BARRERA GonZALEZ, Andrés (1997). «Lengua, identidad y nacionalismo en Cataluña durante la transición». Revista de Antropología Social, 6, p. 109-137.

BEOBIDE EZPELETA, Ignacio Maria (1993). «Nacionalismo vasco: nación y poder». Estudios de Deusto, 41, 1, p. 9-98.

BONET REVÉs, Carles (1997). La falsa ruta. Una crítica independentista. Barcelona: Flor del Vent Edicions.

Colomer, Josep M. (1986). Cataluña como cuestión de Estado. La idea de nación en el pensamiento politico catalán (1939-1979). Madrid: Tecnos.

Conversi, Daniele (1997). The Basques, the Catalans and Spain. Alternative Routes to Nationalist Mobilisation. Londres: Hurst \& Co.

Diez Medrano, Juan (1999). Naciones divididas. Clase, politica y nacionalismo en el País Vasco y Cataluña. Madrid: CIS-Siglo XXI ( $1^{\text {a }}$ ed. en inglés, en 1995).

ETXEBERria, Xabier (1998). «Identidad nacional y violencia. El caso vasco». En Aulestia, K.; EtXeberRia, X.; MARTinez, C.; Velasco, D. Razones contra la violencia. Por la convivencia democrática en el País Vasco, I. Bilbao: Bakeaz, p. 25-82.

FichTE, Johann Gottlieb (1988). Discursos a la nación alemana. Madrid: Tecnos (1 ed. en alemán, 1807-1808).

FusI, Juan Pablo (1984). El País Vasco. Pluralismo y nacionalidad. Madrid: Alianza Editorial.

GEERTZ, Clifford (1987). La interpretación de las culturas. Barcelona: Gedisa (he utilizado la $2^{\mathrm{a}}$ reedición, de 1989; $1^{\mathrm{a}}$ ed. en inglés, en 1973).

HeIBERG, Marianne (1991). La formación de la nación vasca. Madrid: Arias Montano Editores ( $1^{\text {a }}$ ed. en inglés).

KeAting, Michael (1996). Naciones contra el Estado. El nacionalismo de Cataluña, Quebec y Escocia. Barcelona: Ariel ( $1^{\text {a }}$ ed. en inglés, en el mismo año).

KYMLICKA, Will (1996). «Derechos individuales y derechos de grupo en la democracia liberal». Isegoría, 14, p. 5-36.

Letamendia, Francisco (1997). Juego de espejos. Conflictos nacionales centro-periferia. Madrid: Trotta.

LinZ, Juan José (1985). «From Primordialism to Nationalism». En TiRYAKIAN, E.A.; Rogowsky, R. New Nationalisms of the Developed West. Boston: Allen and Unwin, p. 203-253.

LOYER, Barbara (1990). «Les nationalismes basque et catalan. Des représentations géopolitiques différentes». Hérodote, 57, p. 27-50.

MaCClanCY, Jeremy (1988). "The culture of radical Basque nationalism». Anthropology Today, 4, 5, p. 17-19.

MARFANY, Joan-Lluís (1995). La cultura del catalanisme. El nacionalisme català en els seus inicis. Barcelona: Empúries (he utilizado la $2^{\mathrm{a}}$ ed.).

Pujol, Jordi (1993). Pensar Europa. Barcelona: Generalitat de Catalunya, Departament de la Presidència. 
Renaut, Alain (1993). «Lógicas de la nación». En Delannoi, G.; TaguiefF, P.A. Teorias del nacionalismo. Barcelona: Paidós, p. 37-62 ( $1^{\text {a }}$ ed. en francés, en el mismo año).

RUBIRALTA CASAS, Fermí (1997). El nuevo nacionalismo radical. Los casos gallego, catalán y vasco (1959-1973). San Sebastián: Tercera Prensa-Gakoa Liburuak.

SANTIAGO, José (2001). «Las transformaciones de la identidad nacional y la cuestión de la territorialidad en perspectiva comparada. Los casos de Quebec y el País Vasco». Politica y Sociedad, 38, p.153-178.

SERRANO PASCUAL, Araceli (1998). «Manifestaciones étnicas y civico-territoriales de los nacionalismos». REIS, 82, p. 97-125.

SMith, Anthony D. (1994). «Tres conceptos de nación». Revista de Occidente, 161, p. 7-22.

TERMES, Josep (1984). La immigració a Catalunya $i$ altres estudis d'història del nacionalisme català. Barcelona: Empúries.

ZABALO, Julen (1998). «Euskal nazionalismo motak —nazioaren ikuskeraren arabera—. Uztaro, 26, p. 27-46. 